\title{
Warehouse Inventory Management System for the Smooth Delivery of Cargo to Reduce Dwelling Time at the Port of Tanjung Emas Semarang
}

\author{
Elwas Cahya Wahyu Pribadi ${ }^{1}$, Raja Oloan Saut Gurning ${ }^{1}$, and Eko Susanto ${ }^{2}$ \\ ${ }^{1}$ Department of Marine Engineering, Institut Teknologi Sepuluh Nopember, Surabaya \\ ${ }^{2}$ Politeknik Elektronik Negeri Surabaya, Surabaya \\ e-mail: elwascahyawahyupribadi@gmail.com
}

\begin{abstract}
Delivery cargo is a job of moving goods from the pile or a heap in the warehouse, handing it to be arranged on the vehicle and sending it to the receiving warehouse (consignee). The delivery of goods in the form of fertilizer carried out by PT. PUSRI (Pupuk Sriwijaya) at the Port of Tanjung Emas Semarang from the first line warehouse to each branch of the receiving warehouse throughout Indonesia experienced problems. The problem faced in the activities of the cargo delivery is the delay in the process of shipping goods caused by one of them by a bad warehouse inventory management system so that dwelling time is getting longer. Therefore, a good warehouse inventory management system is needed. This system has several functions, among others, as storing detailed information of goods and pointing to the location of goods. Warehouse inventory management system created with the Internet of Things was developed to track the goods / products that were previously recorded. In monitoring all information used Aduino. the web was built to provide comfort and ease in finding goods / products. With this system the cost required is low and efficient and very easy to use.
\end{abstract}

Keywords-Arduino UNO, Delivery Cargo, Dwelling Time, Ethernet Shield, Microcontroller ATmega328, Web Development.

\section{INTRODUCTION}

CEA shipping services are sought because of low cost $\checkmark$ considerations, which can certainly benefit the company in terms of cost efficiency of shipping services. Sea container service is a freight forwarding service or freight forwarding expedition by sea and the transportation model used is either a cargo ship type of pinisi or a type of tugboat and barge [1].

PT. Pelabuhan Indonesia III (Persero) is one of the StateOwned Enterprises (SOEs) engaged in the transportation sector that is given the task, authority and responsibility to manage 43 (forty-three), II, III, and the region. And the provinces in Central Java, East Java, Bali, South Kalimantan, Central Kalimantan, West Nusa Tenggara and East Nusa Tenggara Provinces. Port of Tanjung Emas Semarang is one of the core business segments in PT. Pelabuhan Indonesia III (Persero) which serves container loading and unloading processes which include stevedoring, cargodoring, receiving and delivery activities. In addition to these 4 services, there are also things that need to be considered in operational activities, namely dwelling time.
Dwelling time at the Port of Tanjung Emas Semarang has averaged more than 4 days. It is longer compared to other countries such as Singapore which has a 1.5 day dwelling time, Hong Kong 2 days, France 3 days, Los Angeles, United States 4 days, Australia 3 days, Port Klang, and Malaysia 4 days [2]. One of the factors that determines dwelling time at the port is the post-clearance process for cargo delivery in the form of fertilizer carried out by PT. PUSRI (Fertilizer Sriwijaya) in the first-line warehouse due to poor warehouse inventory [3]. Based on previous research data that the delivery cargo delay occurred in September 2017 to December 2018 there was a delay in goods from September to February to 550 units. The highest delay is in December 2017 and the lowest delay is in September. Then the total Delivery Cargo delays in the 6th month above reached 550 of the total goods sent. It can be concluded that the delivery cargo delays in warehouse line 1 at the Port of Tanjung Emas Semarang are relatively high. Based on Law 17 of 2008 concerning Sailing dwelling time is a national problem that binds several other government agencies such as the Port Health Office, Immigration, Quarantine, Customs and 18 Ministries regarding licensing of imported products [4].

So researchers offer a computerized warehouse inventory management system with smart systems so that it gives us less effort, more efficient and stable results correlated with existing manual systems.

\section{A. Theoritical Background \\ 1) Tanjung Emas Port}

The Port of Tanjung Emas Semarang is one of the core business segments in PT. Indonesian Port III (Persero). in 1985 the first port in Semarang was the Port of Tanjung Emas in the direction of Tugu Muda Semarang is about $5 \mathrm{~km}$ or about 30 minutes by motorcycle / car as shown on Figure 1 .

The addition of facilities carried out does not always have a major effect on ships entering the port, for example large ships entering the port are still limited. Vessels that can dock at the pier are ships that have a $5 \mathrm{~m}$ draft, while those that are more than $5 \mathrm{~m}$ are anchored outside the dock. besides that the depth and width of the pier for ship berths is still limited as well. therefore government support is very important for the sustainability of the port [3]. 


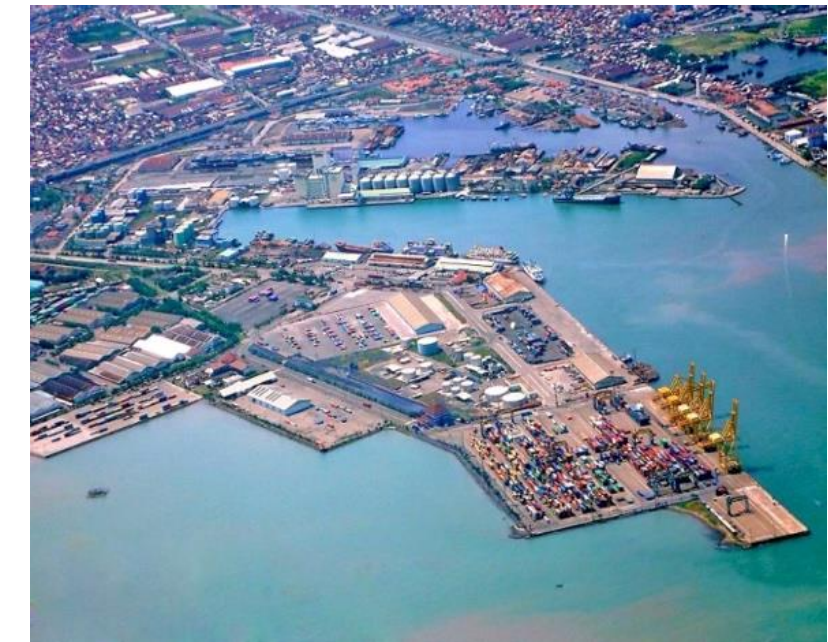

Figure 1. Tanjung Emas Port.

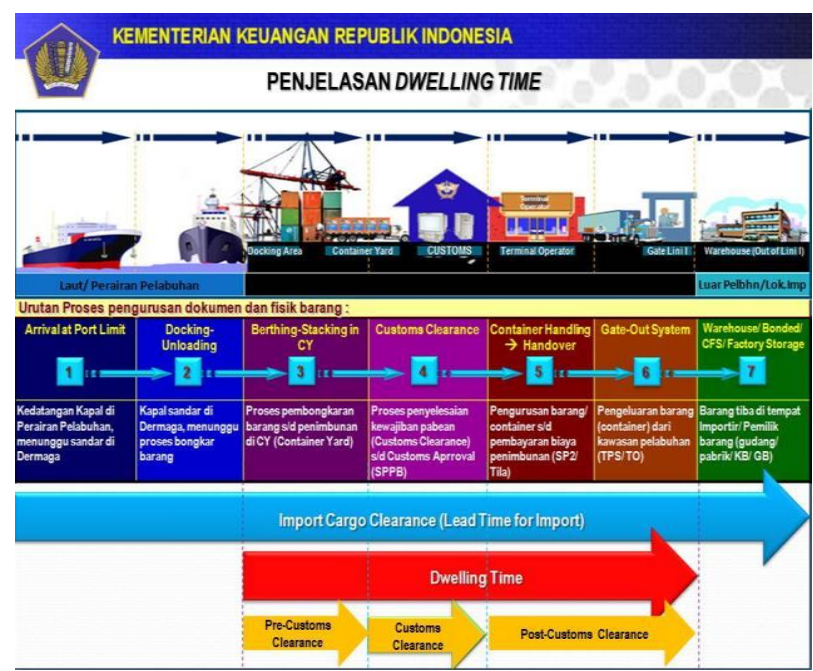

Figure 2. Import Cargo Process.

\section{B. Dwelling Time}

Dwelling time is the time that is calculated starting from a container (container) unloaded and lifted (unloading) from the ship until the container leaves the terminal through the main door. Dwelling time plays an important role because it relates to the length of time that must be passed by the container while still in the terminal to wait for the process of documents, payment, and Customs inspection completed as shown on Figure 2 [5].

\section{Hypertext Markup Language (HTML)}

HyperText Markup Language (HTML) is a markup language used to create a web page, display various information in an Internet web browser and simple hypertext formatting written in ASCII format files in order to produce an integrated appearance. In other words, files are created in word processing software and are stored in the normal ASCII format so that they become web pages with HTML commands.

\section{Hypertext Prepocessor (PHP)}

Hypertext Preprocessor is a scripting language that can be embedded or inserted into HTML. PHP is widely used to program dynamic websites. PHP can be used to build a CMS. PHP is a programming language that runs on a webserver (server side).

\begin{tabular}{|l|l|}
\hline Mikrokontroller & ATMega328 \\
\hline Operasi Voltage & 5 Volt \\
\hline Input Voltage & 7-12 Volt (Rekomedation) \\
\hline Input Voltage & 6-20Volt (limits) \\
\hline I/O & 14 Pin ( 6 Pin for PWM) \\
\hline Current & $50 \mathrm{~mA}$ \\
\hline Flash Memory & $32 \mathrm{~KB}$ \\
\hline Bootloader & SR AM 2 KB \\
\hline EEPROM & $1 \mathrm{~KB}$ \\
\hline Speed & $16 \mathrm{MHz}$ \\
\hline
\end{tabular}

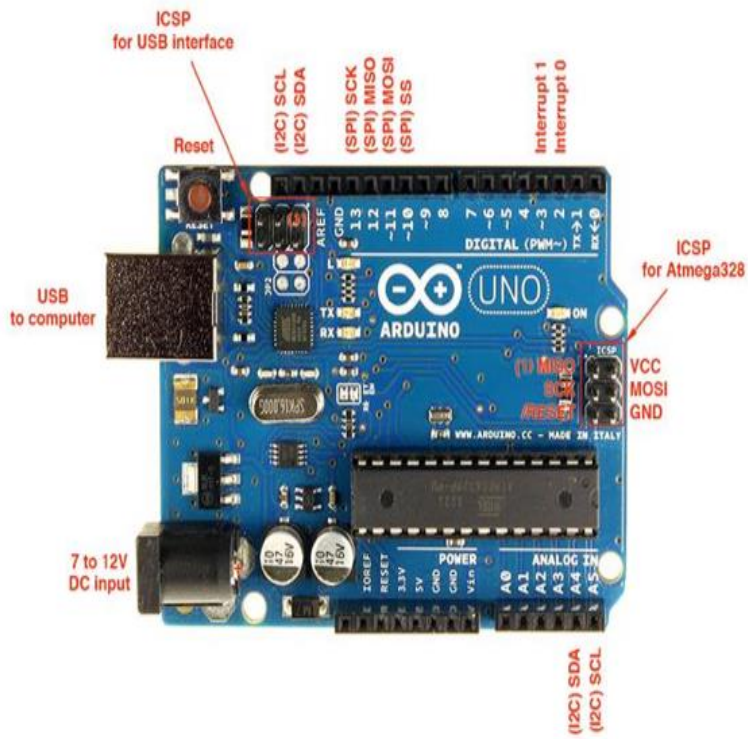

(b)

Figure 3. (a) Description of Arduino Uno; (b) Arduino Uno Pin.

\section{E. UDP User Datagram Protocol}

User Datagram Protocol is a TCP / IP transport layer protocol that supports unreliable communication, without connection (connectionless) between hosts on a network that uses TCP / IP. UDP protocol is a stateless protocol (no place) therefore, the server in this case is used in handling multiple clients at a time. So broadcast and multicast are available with UDP. UDP protocol provides no flow control (congestion control) and congestion control (congestion control), this means that the current blasts as quickly as desired but this situation must be handled by the application program.

\section{F. Arduino}

Uno Arduino is a microcontroller-based board on ATMega328 (the spesification shown on Figure 3). Arduinu Uno has 14 digital input / output pins where 6 pins can be used as PWM outputs, 6 analog inputs, $16 \mathrm{MHz}$ Crystal oscillators, USB connections, power jacks and reset buttons. These pins contain everything needed to support a microcontroller. To use Arduino only need to connect Arduino to the computer using a USB cable or the voltage obtained from the AC-DC adapter or battery.

\section{G. Ethernet Shield}

Arduino Ethernet Shield connects the Arduino board to the internet network, simply plug this in module into the 


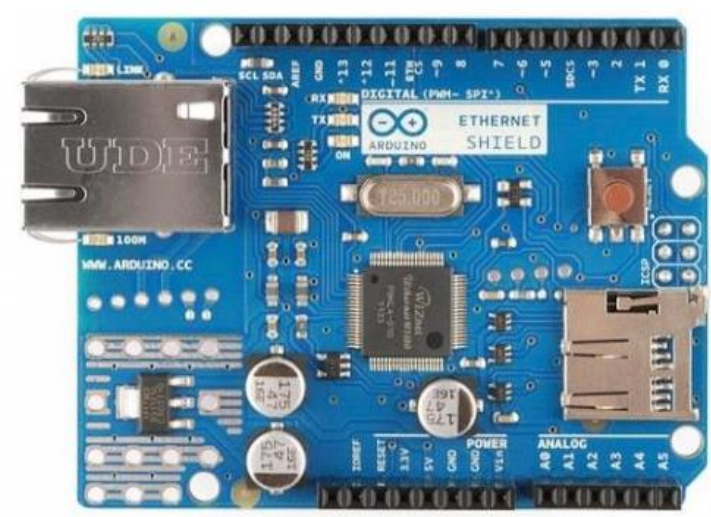

Figure 4. Ethernet shield.

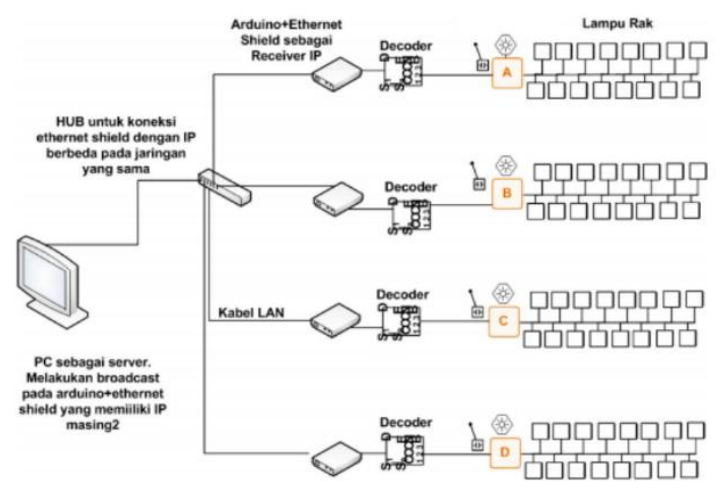

(a)

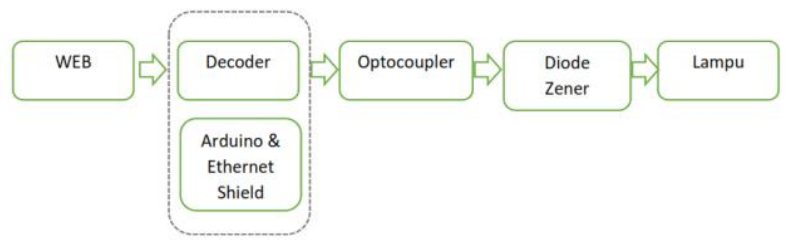

(b)

Figure 5. (a) General system; (b) System block diagram.

Arduino board, connecting it to the network with an RJ-45 cable. As usual, every element from Arduino, both hardware, software, and also available documentation, is available and can be accessed free of charge because it is open source as shown on Figure 4.

\section{METHODOLOGY}

The warehouse inventory management system is an innovation that is realized in the form of a prototype to answer the needs of the field. This warehouse inventory management system makes it easy for users to record items and search goods. An easy search system using the web as a userfriendly interface. The user only needs to find the name of the item and then press the on button on the web, then the light will turn on according to the item code listed. (Shown on Figure 5)

The system generally has a server computer that is used by users that contains a database of cupboards / shelves. To find out the location of an item, the lamp is used as an indicator. A web will be connected to a controller that will work to command and carry out the task of turning on the lights. It is expected that the manufacture of this tool will be able to streamline the use of pins on Arduino where there are only 12 pins capable of lighting up to 16 pieces using a decoder.

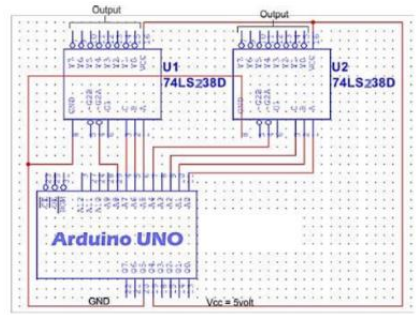

(a)

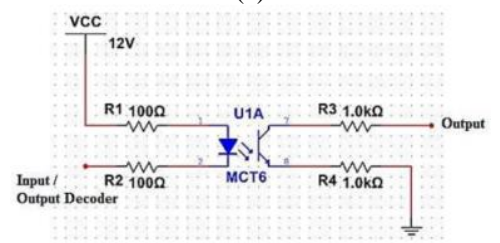

(b)

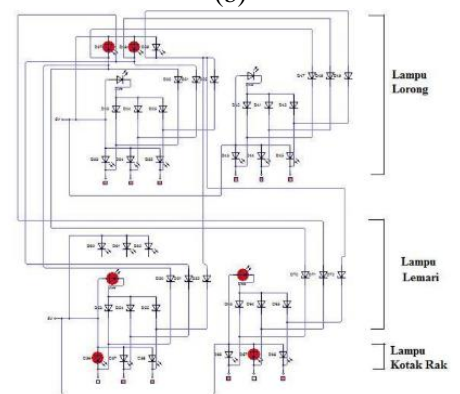

(c)

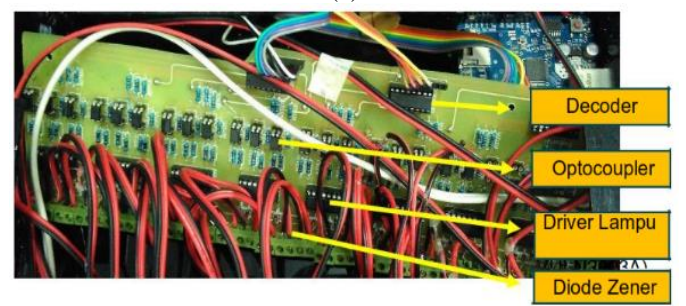

Figure 6. (a) Decoder design ; (b) Schematic Optocoupler; (c) Zener Diode Schematic; (d) Integrated PCB Etching.

In the system diagram Figure 6. The computer is used as a server and website interface. The website is connected to a database that stores all information of goods used to light LEDs on warehouse lines. Arduino microcontroller which has been programmed to turn on the lights. By using the decoder input and decoder output, it is used as a reference to choose a binary value in accordance with the item code. The binary value will be adjusted to which item code should be lit, so that each lamp has its own code to activate the lamp. The use of optocoupler in the system as a component so that the power source of Arduino, 5Volt with 12Volt lamp power source does not interfere with each other. So if to activate the lights on the warehouse line requires the results of the processor on Arduino, with the Arduino resource used is 5 Volt which will cause the lights to dim because the power used is 5 volts while the lamp needs is 12 Volt. Zener diodes are used to direct current.

\section{H. Schematic and PCB Hardware}

In this project there are 3 hardware parts which are combined into one PCB, they are decoder, optocoupler, lamp driver (ULN2003A) and zener diode as shown on Figure 6.

In this research, integration between hardware and web is needed, therefore we need a microcontroller that can bridge this. By using a combination of Arduino Uno with Ethernet Shield. Arduino to provide and adjust the lights based on web input and the Ethernet shield used for communication 


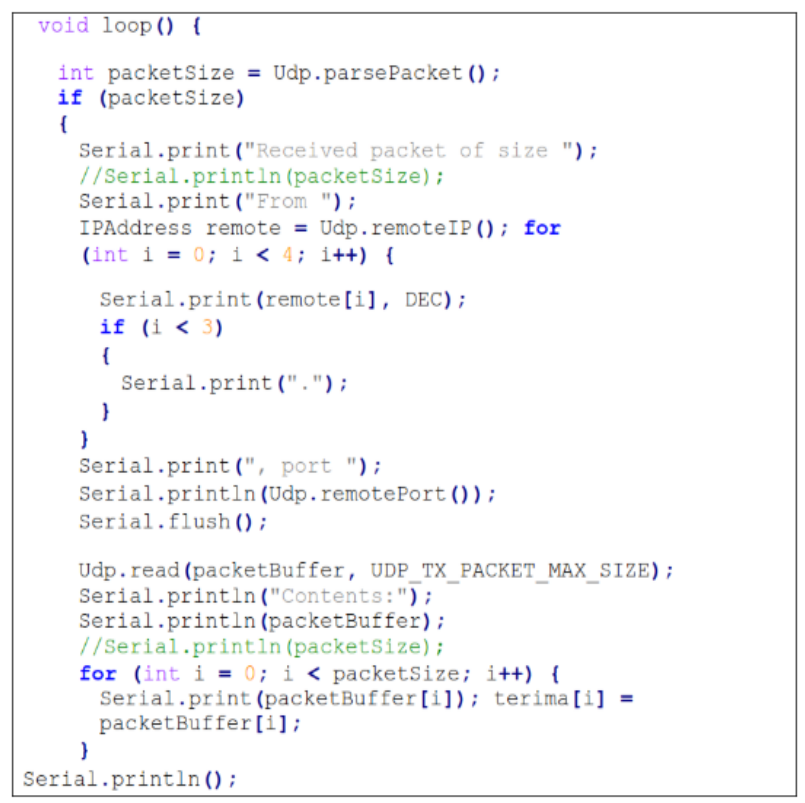

Figure 7. Coding in Arduino IDE.

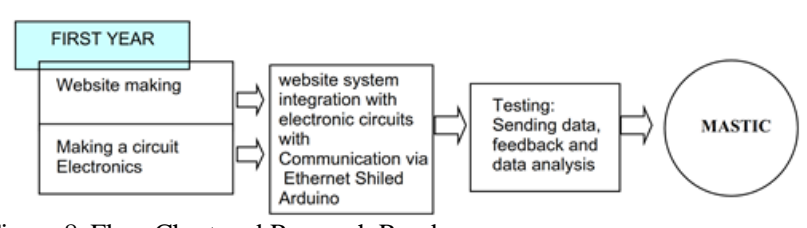

Figure 8. Flow Chart and Research Roadmap.

using LAN cables. The following is an explanation of the program that has been embedded in Arduino and Ethernet Shield.

Ethernet shield is a library that must be used to be able to use LAN. Due to the method of finding this item with a broadcast system to all IPs on the same network, it uses the UDP model. Basically in the network, there are 2 models of communication, namely TCP / IP and UDP.

For UDP, it will send data to all IPs on the same network, but this model has a weakness that is not known whether the data is sent intact or something is lost during the sending process. If applied to this project it has no effect because the data that is sent is only small, that is the character of the location of the goods, so there will be no data losses as shown on Figure 7.

In this loop function is used to send data using Udp which provides information about the package, and its size. In this loop function the input algorithm is accepted and must be responded to. Therefore the data sent in response is data from the location of the lights. For the logic of mapping the number of pins to the address of the lamp using a 1x8 array. If the user lights on a shelf on the web that has the address 1A.01.A.1, there will be 2 addresses on the program, namely IA.01.A. 1 on and IA.01.A.1 off, which is the address for on off lamp. The results are entered into an array with the specified value. When reading the input data string IA.01.A.1on it will be entered in the data array with condition 1 (on), and vice versa. Therefore if there are 8 lights there will be 16 conditions namely 8 on and 8 off.

\section{Flow Chart and Research Roadmap}

The flow chart and research roadmap shown on Figure 8.

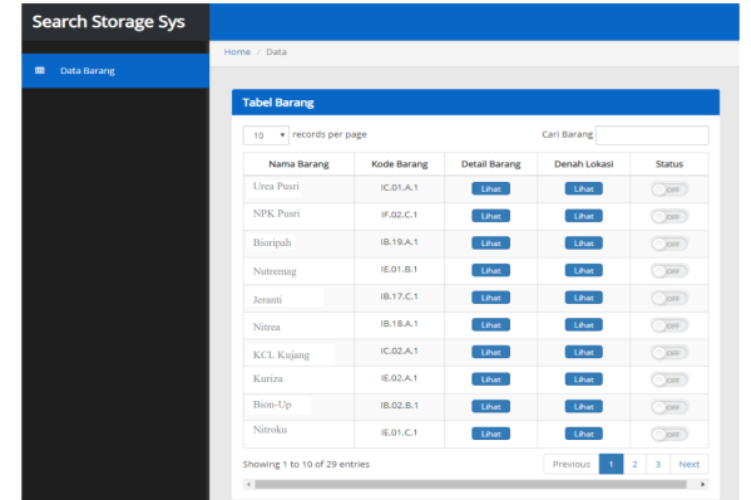

Figure 9. Website Homepage Display.

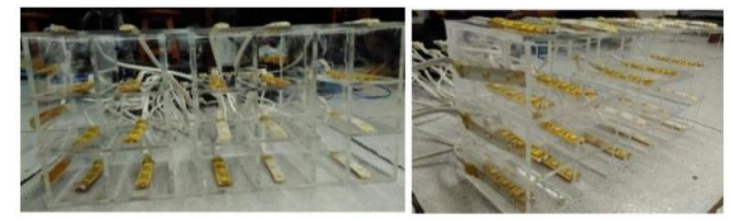

(a)

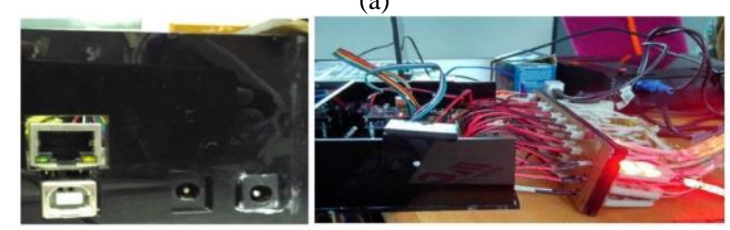

(b)

Figure 10. (a) Rack component; (b) Light controller circuit.

\section{RESULT AND DISCUSSION}

As Figure 9 shows, is the website homepage displayed, which is a search (data) item. By default, when a web page is opened, the display will be directed to the item search page. On the item data search page, the item data will be displayed on a shelf in tabular form. The data is obtained from calling data elements in the database using localhost. The web will browse the database in question, and read one by one the data to be displayed in the table. In the table, there are 3 menus that can be operated, which are looking at the details of goods, see the location of the item on the shelf, and the switch to turn on the lights.

When the user presses the On / Off switch button, the program will record the item code of the item in question then directed to the process function, where in this function will be checked, whether the switch is on or off. If it is on then the item code will be given an "on" header whereas if it is Off, then the item code will be given an "off" header. Then the data is sent to the UDPsend.php file. In this function, data containing item codes and headers will be sent using UDP data transmission mode.

In this component search system there are 2 main parts namely hardware and software interfaces. For hardware, namely communication that is intertwined using UDP communication.

From testing to communication between software and the web using UDP is $100 \%$ successful. The indicator that the data transmission is successful, from the lights and the serial feature on Arduino, shows that the data sent is in the form of an item code as shown on Figure 10. 
$2^{\text {nd }}$ Maritime Safety International Conference (MASTIC) 2020 July $18^{\text {th }}, 2020$, Surabaya

\section{CONCLUSION}

Based on the Warehouse Inventory Management System and the results of the model made, it can be concluded the things as follows:

1) The new inventory management system model design can collect data.

2) Design a new inventory management system model can speed up the search for goods so that dwelling time decreases.

\section{REFERENCES}

[1] A. M. Fadli, "Design of Search Dwelling Time for Makassar Cargo Terminal's Model System in PT. Pelabuhan Indonesia IV (Persero)," Makassar, 2017.

[2] A. Artakusuma, "Analysis of Import Container Dwelling Time at the Jakarta International Container Terminal (JICT) Port of Tanjung Priok," Bandung, 2012.

[3] W. S. Utomo, "Effectiveness of Line 1 Warehouse Against Cargo Delivery Activities to Reduce Dwelling Time at the Port of Tanjung Emas Semarang," Semarang, 2019.

[4] Pemerintah Republik Indonesia, "Law of the Republic of Indonesia No.17 of 2008 concerning Shipping," Jakarta, 2008.

[5] World Bank, "Why Cargo Dwell Time Matters in Trade," Washington D.C., 2011 